\title{
Personality features, dissociation, self-stigma, hope, and the complex treatment of depressive disorder
}

\author{
This article was published in the following Dove Press journal: \\ Neuropsychiatric Disease and Treatment \\ 7 October 2016 \\ Number of times this article has been viewed
}

\author{
Jan Prasko' \\ Marie Ociskova' \\ Ales Grambal' \\ Zuzana Sigmundova' \\ Petra Kasalova' \\ Marketa Marackova' \\ Michaela Holubova ${ }^{1,2}$ \\ Kristyna Vrbova' \\ Klara Latalova' \\ Milos Slepecky ${ }^{3}$ \\ 'Department of Psychiatry, Faculty \\ of Medicine and Dentistry, Palacky \\ University Olomouc, University \\ Hospital Olomouc, Olomouc, \\ ${ }^{2}$ Department of Psychiatry, Hospital \\ Liberec, Liberec, Czech Republic; \\ ${ }^{3}$ Department of Psychology Sciences, \\ Faculty of Social Science and Health \\ Care, Constantine the Philosopher \\ University in Nitra, Nitra, Slovak \\ Republic
}

Objective: Identifying the predictors of response to psychiatric and psychotherapeutic treatments may be useful for increasing treatment efficacy in pharmacoresistant depressive patients. The goal of this study was to examine the influence of dissociation, hope, personality trait, and selected demographic factors in treatment response of this group of patients.

Methods: Pharmacoresistant depressive inpatients were enrolled in the study. All patients completed Clinical Global Impression - both objective and subjective form (CGI), Beck Depression Inventory (BDI), and Beck Anxiety Inventory (BAI) at baseline and after 6 weeks of combined pharmacotherapy and psychotherapy (group cognitive-behavioral or group psychodynamic) treatment as an outcome measures. The Internalized Stigma of Mental Illness Scale (ISMI), Dissociative Experience Scale (DES), Adult Dispositional Hope Scale (ADHS), and Temperament and Character Inventory (TCI-R) were completed at the start of the treatment with the intention to find the predictors of treatment efficacy.

Results: The study included 72 patients who were hospitalized for the pharmacoresistant major depression; 63 of them completed the study. The mean scores of BDI-II, BAI, subjCGI, and objCGI significantly decreased during the treatment. BDI-II relative change statistically significantly correlated with the total ISMI score, Discrimination Experience (ISMI subscale), and Harm Avoidance (TCI-R personality trait). According to stepwise regression, the strongest factors connected to BDI-II relative change were the duration of the disorder and Discrimination Experience (domain of ISMI). ObjCGI relative change significantly correlated with the level of dissociation (DES), the total ISMI score, hope in ADHS total score, and Self-Directedness (TCI-R). According to stepwise regression, the strongest factor connected to objCGI relative change was Discrimination Experience (domain of ISMI). The existence of comorbid personality disorder did not influence the treatment response.

Conclusion: According to the results of the present study, patients with pharmacoresistant depressive disorders, who have had more experience with discrimination because of their mental struggles, showed a poorer response to treatment.

Keywords: depressive disorder, cognitive-behavioral therapy, pharmacotherapy, psychodynamic therapy, treatment efficacy, dissociation, personality features, hope, self-stigma

\section{Introduction}

Psychotherapeutic and biological approaches have proven their effectiveness in the treatment of depressive disorders. Approximately $40 \%-70 \%$ of the patients who are suffering from depression react positively to the treatment with the antidepressant for at least 2 months..$^{1-5}$ Approximately $80 \%$ of them respond to the first or second choice of a recommended antidepressant. Despite the relatively high antidepressant efficacy, the level of treatment resistance is relatively high. Approximately $15 \%-20 \%$ of those who do not respond to the treatment are supposed to suffer from treatment-resistant depression. ${ }^{6-10}$
Correspondence: Jan Prasko Department of Psychiatry, Faculty of Medicine and Dentistry, Palacky University Olomouc, University Hospital, I. P. Pavlova 6, 77520 Olomouc, Czech Republic Email praskojan@seznam.cz (c) (i) (5) 2016 Prasko et al. This work is published and licensed by Dove Medical Press Limited. The full terms of this license are available at https://www.dovepress.com/terms.php cc. hereby accept the Terms. Non-commercial uses of the work are permitted without any further permission from Dove Medical Press Limited, provided the work is properly attributed. For permission for commercial use of this work, please see paragraphs 4.2 and 5 of our Terms (https://www.dovepress.com/terms.php). 
In addition to the biological factors, the treatment resistance issue may also be relevant to study the demographic and psychosocial factors, which influenced the patients. Based on the clinical experience, following factors are included: 1) demographic factors such as sex, occupation, partner, and marital status, the age or the disorder onset, and the duration of the disorder; 2) psychological factors such as the presence of personality traits or the comorbidity with the personality disorders, dissociation, and hope; 3) psychosocial factor such as self-stigma. It is important to study these factors and explore their clinical relevance exceptionally in patients with treatment resistance.

\section{Personality}

A common clinical experience is that personality could accelerate or hinder the outcome of the treatment of depressive disorder. A dimensional model of personality designed by Cloninger et $\mathrm{al}^{11}$ has been repeatedly studied in patients with major depression and has been recognized to be important. Cloninger et al's ${ }^{11}$ Temperament and Character Inventory (TCI-R) assesses four temperament dimensions: novelty seeking, harm avoidance, reward dependence, and persistence, and three dimensions of character: self-directedness (SD), cooperativeness, and self-transcendence. ${ }^{11}$ The severity of depression positively correlated with Harm Avoidance scores in many studies. ${ }^{12-23}$ In addition, the scores were changed by depression improvement and during the treatment with antidepressant. ${ }^{13,16,17,24}$ In a meta-analysis of major depressive disorder and personality traits, Harm Avoidance rates displayed a definite negative change from baseline to endpoint. ${ }^{25}$ Depressed patients also present low scores of SD. The severity of depression correlates negatively with SD in several reports. ${ }^{14-22,26}$ Depressive patients with low scores of Harm Avoidance incline to reach relatively good results in the treatment. ${ }^{27,28}$ Typical TCI-R scores representing a satisfactory outcome demonstrate decrease in Harm Avoidance and Self-Transcendence rates and increase in SD and Cooperativeness rates during the treatment. ${ }^{29}$ In addition, the Harm Avoidance scores in treatment-resistant patients are significantly higher at the beginning of the treatment than the scores of the group with a favorable outcome. ${ }^{28,30}$ Also, no significant changes in personality features were detected in patients with poor outcome. ${ }^{29}$ Both nonresponders and responders presented higher Harm Avoidance rates and decreased SD and Cooperativeness rates on the inventory. ${ }^{16}$

\section{Comorbid personality disorder}

Another important factor that can affect the resistance to treatment is the presence of personality disorder. Comorbidity of depression with a personality disorder has been studied frequently. Depressive individuals with comorbid personality disorder commit more suicidal attempts and have a worse reaction to antidepressant treatment in comparison with people with depression alone. ${ }^{31,32}$ In our previous study, it was found that there were no significant differences between these two groups in the treatment results associated with the number of depressive episodes, the duration of hospitalizations, doses of medication, or comorbid personality disorder. ${ }^{33}$ Other studies found comparable findings suggesting that comorbidity with a personality disorder has no negative influence on the depression treatment. ${ }^{12,34-37}$ The negative effect of comorbid personality disorder is more evident in depression comorbidity with two or more personality disorders, which was shown in some studies as taking longer time for getting to remission in these persons..$^{31,38,39}$ However, these results are not consistent with the studies of psychotherapy. Levenson et $\mathrm{al}^{39}$ investigated depressive patients who were treated with interpersonal therapy. They found no differences in the results of treatment regarding the presence of one comorbid personality disorder (except borderline personality disorder). O'Leary and Costello found that comorbidity with a personality disorder predicts an extended time for reaching remission in the acute depression treatment, but the presence of personality disorder was not a predictor of more frequent relapses in the 18 -month follow-up. ${ }^{40}$ From the personality disorders, borderline personality disorder is recognized to be a predictor of later bipolar and unipolar depression. ${ }^{41}$ Related to depressed patients without borderline personality disorder, the patients with a comorbid borderline personality disorder had an earlier time of onset, more depressive episodes, and a higher number of previous suicide attempts, prevalence of anxiety disorders comorbidity, and substance use disorders. ${ }^{42}$ Different results regarding comorbid personality disorder may be due to various assessment methods (using different methods of assessment), several types of treatment (only pharmacotherapy or psychotherapy, various psychotherapeutic approaches, or different setting), and specifics of the patient (coping strategies, the rate of cooperation, personality characteristics, voluntariness of hospitalization, pharmacoresistance, etc).

\section{Dissociation}

Another factor contributing to treatment resistance in the depressive individuals is the preference of dissociation as a coping strategy. Dissociation is a defense mechanism used to cope with unbearable emotional states. ${ }^{43,44}$ According to Diagnostic and Statistical Manual of Mental Disorders, fifth edition, 
dissociation is described as the deterioration of the integrative functions of consciousness, as the perception of memory, identity, and environment. ${ }^{45}$ Usually, these experiences altogether constituted wholeness in the stream of mind ${ }^{46,47}$ Dissociation prevents the integration of experiences and information and can be characterized by amnesia, depersonalization, or derealization. ${ }^{48}$ It is a strategy commonly display by the patients with dissociative disorders, ${ }^{49}$ panic disorder, ${ }^{50} \mathrm{OCD},{ }^{51-53}$ depressive disorder, and borderline personality disorder. ${ }^{54,55}$ People perceive dissociation as a dispersion in the wholeness of a sense of self. This dispersion emerges as the disintegration of the harmony of chronological, biographic, and perceptive identity. ${ }^{47,56}$ Dissociation is showed to be one of the essential psychological factors that influence the treatment efficacy. ${ }^{57,58}$

In the etiology of dissociation, traumatic experiences, such as childhood abuse, take a major place. ${ }^{59-61}$ A history of childhood trauma is connected to psychiatric problems in adulthood, mostly to depression. ${ }^{62}$ Van Veen et a ${ }^{63}$ examined relations of childhood trauma, childhood life events, and recent life events in a patient with or without depressive or anxiety disorders. Strong associations were seen for emotional neglect with anhedonic depression and sexual abuse with anxious arousal. Emotional trauma in childhood has a higher impact on interpersonal problems in adults with depression than childhood physical trauma. ${ }^{64}$ History of abuse or/and neglect during childhood is associated with a risk factor in the pathogenesis of dissociation. ${ }^{65-70}$ In a related perspective, tension reduction theory suggests that dissociation is used to self-regulate unpleasant emotions. ${ }^{71,72}$

Bersani et $\mathrm{al}^{73}$ assessed the presence of dissociative symptoms in women suffering from mood and anxiety disorders and correlated them with disorder severity and personality traits. Depressive signs positively correlated with the total rates of Dissociative Experience Scale (DES). Sar et $\mathrm{al}^{74}$ screened the prevalence and correlates of dissociative disorders among depressive women in the general population. The prevalence of present major depressive episode was $\sim 10.0 \%$. Of the women, $26(40.6 \%)$ had the lifetime diagnosis of a Diagnostic and Statistical Manual of Mental Disorders, fifth edition, dissociative disorder, yielding a prevalence of $4.1 \%$ for dissociative depression. The dissociative depression group frequently reported the early termination of school education and childhood sexual abuse.

\section{Hope}

Another important element that contribute to the effectiveness of therapy is hope. The construct of hope has received increasing attention over the last three decades. ${ }^{75-77}$ The theory is grounded on the notion that individuals are inherently goaldirected and that, in search of their goals, they involve in two related cognitive and motivational processes: 1) pathways thinking, which contains thinking about ways to reach goals and 2) agency, which involves motivation toward achieving the goals and sustaining despite frustration and failure. ${ }^{78}$ Previous research has found that high scores of hope are positively correlated with better mood, physical health, and better ability to cope with illness. ${ }^{78-84}$

\section{Stigma of mental illness}

Many depressive patients have a stigma about depression, which may impede treatment seeking and treatment adherence. ${ }^{85-87}$ Self-stigma and fear of stigmatization by others often lead to avoidance of treatment, its premature termination, and poor adherence. ${ }^{87}$ Higher depression severity was connected with amplified self-stigma associated with the treatment and the psychiatric diagnosis. Higher self-stigma was linked with more negative beliefs about medications and more positive beliefs about psychotherapy. ${ }^{86}$ Borecki et al ${ }^{88}$ showed the importance of personality resources in coping with stigma in depressive patients and points to secrecy as an important hidden feature in these processes. Stigma experienced by the individual is connected not only to the external indicators of public stigmatization and the severity of depression but also to the personal features of the patients. One consequence of these accepted prejudices is reduced treatment effectiveness. ${ }^{58}$ The effect of self-stigma to treatment efficacy in patients with depressive disorder is less clear.

\section{Aim of the study}

The objective of this research is to explore the influence of hope, self-stigma, dissociation, and personality features on the treatment efficacy of patients with depressive disorder and with or without comorbid personality disorders.

\section{Methods \\ Participants}

A total of 72 antidepressant treatment-resistant depressive patients from outpatient setting were enrolled in this inpatient study (Table 1). The research sample consisted of inpatients who were hospitalized in the psychiatric department and met the ICD-10 research criteria for the depressive disorder. ${ }^{89}$ Two senior-level psychiatrists assessed patients' psychopathology by Clinical Global Impression (CGI) and Mini-International Neuropsychiatric Interview (M.I.N.I.). The diagnostic criteria of ICD-10 (1996) were used as a primary diagnostic tool; the diagnostic M.I.N.I. was used 
Table I Inclusion and exclusion criteria

Inclusion criteria
- Diagnosis of depressive disorder according to research ICD-I0 criteria
(ICD-10 I996)
- Both sexes
- Age between 18 and 65 years
- Informal consent
Exclusion criteria
- Severe somatic illness
- Organic brain disease
- Bipolar affective disorder lifetime
- Schizophrenia lifetime
- Mental retardation
- Acute suicidal behavior or plan

to confirm the diagnosis and comorbidities. ${ }^{90}$ The patients were all somatically fit and free of drug or alcohol abuse. Inclusion and exclusion criteria for the study are listed in Table 1. Patients were considered to be pharmacoresistant if they were treated for a minimum of 6 months of adequate doses of minimum two different antidepressants before being admitted to the hospital.

\section{Measurements}

The patients, who agreed to contribute to the study, signed an informed consent form and completed several scales. The following methods were completed at the start and at the end of the treatment:

- BDI-II (Beck Depression Inventory, second edition) This scale includes 21 items - depressive symptoms - in which patients choose perceived symptoms and their severity during the last week.$^{91}$ Internal consistency of the scale is higher in psychiatric population $(\alpha=0.86)$ than in general population $(\alpha=0.81) .{ }^{91}$ The Czech version was published by Preiss and Vacir. ${ }^{92}$ The relative change in BDI-II is the main outcome criterion for the improvement in the present study. This criterion is defined as a difference between the last and the first evaluation divided by the initial assessment.

- CGI - This scale is used for global assessment of the severity of psychopathology. ${ }^{93}$ The initial assessment is performed by the patient's psychologist or psychiatrist using the objective form of the scale (objCGI). The patient also assesses himself/herself by the subjective version (subjCGI), which includes seven levels of severity of the psychopathology. Internal consistency of the scale seems satisfactory. ${ }^{94}$

- BAI (Beck Anxiety Inventory) - This scale is based on 21 items - anxiety symptoms - on a 4-point Likert scale. ${ }^{95}$ The patients choose perceived symptoms and their severity during the last week. This method has excellent internal consistency (mean $\alpha=0.91$ ). ${ }^{96}$ The validation of the Czech translation is currently in progress. Its Cronbach alpha is $0.92 .{ }^{97}$

The following methods were completed only before the treatment:

- TCI-R - This inventory measures four dimensions of temperament, three dimensions of character, and a number of their subscales. ${ }^{11,19,98-100}$ The revised version consists of 240 items out of which five are check items. The temperament domains are Novelty Seeking, Harm Avoidance, Reward Dependence, and Persistence, and the character domains are Self-Directedness, Cooperation, and Self-Transcendence. ${ }^{101}$ Reliability of the Czech translation of the method is also satisfactory. ${ }^{102}$

- ADHS (Adult Dispositional Hope Scale) - This scale consists of 12 items - four of them focus on pathway thinking (ie, the ability to find ways to achieve desired goals), another four relate to agency (ie, a sense of inner motivation and will achieve the goals), and the last four items are distractors. ${ }^{76}$ Patients select one of the 8 points on a scale agreeing to the level of an agreement with each statement. The internal consistency of the Czech standardization of the scale is good $(\alpha=0.82$ for the general population, $\alpha=0.85$ for psychiatric population). ${ }^{103}$

- ISMI (Internalized Stigma of Mental Illness) - This questionnaire consists of 29 statements with a 4-point scale measuring the level of the agreement with them. ${ }^{104}$ The scale measures five facets of internalized stigma - alienation, perceived discrimination, stereotype endorsement, social withdrawal, and resistance to stigma. Cronbach alpha of the method is excellent $(\alpha=0.90)$. The questionnaire was standardized in Czech by Ociskova et al. ${ }^{105}$ The Czech version of the scale has a similar internal consistency $(\alpha=0.91) .{ }^{105}$

- DES - This method describes 28 dissociative experiences, and patients mark a spot on a $10-\mathrm{cm}$ line according to the frequency of experiencing the symptoms. ${ }^{106}$ Current modifications of the dissociation model have arrived at the difference between a dimensional, nonpathological type and a discontinuous, pathological class of dissociation, which can be recognized by a subgroup of eight items of the DES, the DES-Taxon (DES-T). ${ }^{107}$ This subscale consists of eight out of the 28 DES items (items 3, 5, 7, 8, 12, 13, 22, and 27). ${ }^{108}$ The Czech version of the scale is similar to the original version regarding its validity, test-retest reliability, and the factor structure. ${ }^{109}$ 
- The demographic questionnaire consists of basic information such as sex, age, age of disease onset, number of hospitalizations, employment status, education, pension status, duration of attendance at the outpatient clinic, time since last hospitalization, current medication, number of visited psychiatrists, and discontinuation of drugs in the past (recommended by a psychiatrist or arbitrarily).

The treatment response was defined as a decrease of $35 \%$ of symptomatology or more. Remission was defined as a score 1 or 2 on the objCGI-severity or $<10$ on the BDI-II.

\section{Methods of the treatment}

All patients were hospitalized for 6 weeks in the psychotherapeutic department of the Department of Psychiatry, University Hospital Olomouc. They were treated by the group cognitive-behavioral therapy (CBT) or brief psychodynamic therapy in combination with pharmacotherapy. Patients used antidepressants, mainly SSRIs, with mean daily dosage of $49.74 \pm 28.42 \mathrm{mg}$ of paroxetine index $(n=59)$, mean daily dosage of anxiolytics $0.82 \pm 0.89 \mathrm{mg}(\mathrm{n}=22)$ of alprazolam index, and mean daily dosage of antipsychotics $1.40 \pm 1.45 \mathrm{mg}(\mathrm{n}=17)$ of risperidone index at the beginning of the treatment. The change of antidepressant and its dosage were rare, mostly because of optimization of dosages because of side effects. At the end of the treatment, the mean daily dosage of antidepressant was $47.57 \pm 31.25 \mathrm{mg}$. There was an effort to decrease or stop medication with anxiolytics the number of patients treated with benzodiazepines drops from 22 at the beginning to 10 at the end, with a mean daily dosage of $0.438 \pm 0.456 \mathrm{mg}$ of alprazolam index. On the other hand, seven more patients were additionally prescribed antipsychotic medication during the treatment to augment the antidepressant effect, with a mean daily dosage of $1.029 \pm 0.8258 \mathrm{mg}$ of risperidone index. All patients were treated with standard doses of previously used medication for depressive disorders. Patients attended the 30 group sessions (CBT or short psychodynamic therapy) and five individual sessions. The psychotherapeutic group protocol also included drama therapy, progressive muscle relaxation, mental imagery, and physical activities.

\section{Statistics}

Statistics was calculated by using statistical software SPSS 24.0 (IBM Corporation, Armonk, NY, USA) and the Prism (GraphPad PRISM version 5.0; http://www.graphpad. com/prism/prism.htm; GraphPad Software, Inc., La Jolla, CA, USA). The applied statistical procedures were descriptive statistics for the demographic data, mean scores, and a character of data distribution. Differences between scores measured at the start and the end of the treatment were calculated by parametric or nonparametric pair Student's $t$-tests. The chi-square tests were used for the categorical variables. Differences in the declines of the scores in patients with and without comorbid personality disorder and patients undergoing the group CBT or short-term psychodynamic therapy were calculated by two-way ANOVA, followed by Bonferroni's Multiple Comparison Test. Relationships between treatment outcome and other factors were considered by correlations and a multiple stepwise regression analysis. Differences were considered to be significant when $P$-values were $<0.05$.

\section{Ethics statement}

The investigation was performed in agreement with the latest version of the Helsinki Declaration and the Guideline for Good Clinical Practice. ${ }^{110}$ The local ethical committee of University Palacky Olomouc, Faculty of Medicine and Dentistry, accepted the study. Written informed consent was obtained from all participants after the procedures had been fully explained.

\section{Results Sample description}

The research was conducted from January 2012 to July 2014 in the psychotherapeutic department in Olomouc. During this period, 72 of 442 treated patients met the inclusion criteria for the study (Table 2). Nine patients dropped out from the study because of various reasons: all of them stopped the treatment in psychotherapeutic department prematurely, three of them because of dislike of the psychotherapeutic program and preferring only the pharmacotherapy, in two patients, the diagnosis was changed (one to bipolar disorder and second to organic affective disorder), two were readmitted to the other department because of severe psychotic depression, and one refused the fulfilling questionnaires.

\section{Rating scales during the treatment}

There was a statistically significant improvement in all rating scales during the treatment (Table 3, Figure 1).

Treatment response defined as $>35 \%$ improvement in BDI-II reached 37 patients $(58.7 \%)$, and 23 patients $(36.5 \%)$ reached remission (the last subjCGI score 1 or 2 ). The level of hope according to the ADHS total score was 31.56 \pm 12.57 , with subscore Pathway Thinking 16.81 \pm 6.39 , and Agency 14.86 \pm 6.69 (Table 2). The level of self-stigma in total score of ISMI was $68.45 \pm 14.86$, with subscores: Alienation 16.11 \pm 4.17 , Stereotype Endorsement 14.37 \pm 3.39 , 
Table 2 Demographic and clinical data

\begin{tabular}{|c|c|c|c|c|}
\hline Variable & All patients $(n=72)$ & Dropouts $(n=9)$ & Finished study $(n=63)$ & Statistic: dropouts vs finished \\
\hline Age & $41.53 \pm 13.26$ & $36.33 \pm 16.65$ & $42.27 \pm 12.69$ & Unpaired $t$-test: $t=1.262, d f=70 ; n s$ \\
\hline $\operatorname{Sex}(M / F)$ & $21 / 51$ & $\mathrm{I} / 8$ & $20 / 43$ & Fisher's exact test: ns \\
\hline Age of the onset of the disorder & $32.81 \pm 16.06$ & $30.33 \pm 19.33$ & $33.16 \pm 15.69$ & Unpaired $t$-test; $t=0.4910, d f=70 ; n s$ \\
\hline Duration of the disorder & $8.63 \pm 8.97$ & $5.94 \pm 6.10$ & $9.02 \pm 9.28$ & Mann-Whitney test: $M W U=234.5 ;$ ns \\
\hline Heredity: no/yes & $38 / 34$ & $5 / 4$ & $33 / 30$ & Fisher's exact test: ns \\
\hline $\begin{array}{l}\text { Education basic/vocational training/ } \\
\text { secondary school/university }\end{array}$ & $13 / 16 / 37 / 6$ & $4 / 2 / 3 / 1$ & $9 / 16 / 37 / 6$ & Chi-square: ns \\
\hline Employed/unemployed & $34 / 38$ & $4 / 5$ & $30 / 33$ & Fisher's exact test: ns \\
\hline No pension/pension & $54 / 18$ & $6 / 3$ & $48 / 15$ & Fisher's exact test: ns \\
\hline $\begin{array}{l}\text { Marital status: single/married/ } \\
\text { divorced/widowed }\end{array}$ & $25 / 25 / 15 / 7$ & $7 / 1 / 0 / 1$ & $18 / 24 / 15 / 6$ & Chi-square: $P<0.05$ \\
\hline Without a partner/with a partner & $30 / 42$ & $4 / 5$ & $26 / 37$ & Fisher's exact test: ns \\
\hline Number of previous hospitalizations & $2.18 \pm 1.36$ & $2.67 \pm 2.00$ & $2.11 \pm 1.25$ & Mann-Whitney test; MW U=25I; ns \\
\hline BDI-0 & $27.63 \pm 8.92$ & $24.11 \pm 10.06$ & $27.67 \pm 9.36$ & Unpaired $t$-test; $t=1.056, d f=70 ; \mathrm{ns}$ \\
\hline BAI-0 & $27.34 \pm 11.42$ & $30.75 \pm 9.32$ & $26.90 \pm 11.65$ & Unpaired $t$-test; $t=0.896 \mathrm{I}, d f=70 ; \mathrm{ns}$ \\
\hline objCGI-Severity-0 & $4.38 \pm 1.06$ & $4.25 \pm 0.71$ & $4.40 \pm I . I$ & Mann-Whitney test; MW U=233; ns \\
\hline subjCGI-Severity-0 & $4.8 \mathrm{I} \pm \mathrm{I} .1 \mathrm{I}$ & $4.7 I \pm 0.95$ & $4.83 \pm 1.13$ & Mann-Whitney test; $M W U=210$; ns \\
\hline DES & $|7.3| \pm \mid 4.60$ & $18.68 \pm 17.85$ & $17.17 \pm 14.42$ & Unpaired $t$-test; $t=0.2400, d f=70 ; n s$ \\
\hline DES-T & $10.74 \pm 14.05$ & $11.99 \pm 17.94$ & $10.62 \pm 13.79$ & Mann-Whitney test; MW U=I77.5; ns \\
\hline NS & $96.00 \pm 13.42$ & $93.00 \pm 11.52$ & $96.36 \pm 13.67$ & Unpaired $t$-test; $t=0.6227, d f=70 ; \mathrm{ns}$ \\
\hline $\mathrm{HA}$ & $125.70 \pm 18.17$ & $123.40 \pm 1 \mid .00$ & $126.00 \pm 18.89$ & Unpaired $t$-test; $t=0.3469, d f=70 ; \mathrm{ns}$ \\
\hline RD & $94.97 \pm 13.42$ & $95.86 \pm 16.82$ & $94.86 \pm 13.13$ & Unpaired $t$-test; $t=0.1837, d f=70 ; n s$ \\
\hline PS & $98.18 \pm 22.98$ & $93.57 \pm 12.79$ & $98.73 \pm 23.91$ & Unpaired $t$-test; $t=0.5585, d f=70 ; n s$ \\
\hline SD & $|20.50 \pm| 7.3 \mid$ & $123.10 \pm 15.00$ & $120.10 \pm 17.65$ & Unpaired $t$-test; $t=0.4320, d f=70 ; \mathrm{ns}$ \\
\hline $\mathrm{CO}$ & $|23.20 \pm| 4.88$ & $|20.30 \pm 2| .5 \mid$ & $|23.60 \pm| 4.1 \mid$ & Unpaired $t$-test; $t=0.4320, d f=70 ; n s$ \\
\hline ST & $66.26 \pm 13.88$ & $65.57 \pm 9.90$ & $66.34 \pm 14.34$ & Unpaired $t$-test; $t=0.1373, d f=70 ; n s$ \\
\hline ADHS - total score & $31.29 \pm 12.03$ & $28.67 \pm 3.98$ & $31.56 \pm 12.57$ & Unpaired $t$-test; $t=0.5576, d f=70 ; \mathrm{ns}$ \\
\hline ISMI - total score & $68.47 \pm 14.39$ & $68.63 \pm 10.85$ & $68.45 \pm 14.86$ & Unpaired $t$-test; $t=0.03183, \mathrm{df}=68 ; \mathrm{ns}$ \\
\hline
\end{tabular}

Note: Data are presented as mean \pm standard deviation.

Abbreviations: BAI, Beck Anxiety Inventory; BDI, Beck Depression Inventory; CO, Cooperation; DES, Dissocative Experience Scale; df, degrees of freedom; F, females; HA, Harm Avoidance; ISMI, Internalized Stigma of Mental Illness; M, males; objCGI, Clinical Global Impression - Severity, psychiatrist evaluation; subjCGI, Clinical Global Impression - Severity of the disorder, patient evaluation; NS, Novelty Seeking; ns, not significant; PS, Persistence; RD, Reward Dependence; SD, Self-Directednes; ST, SelfTranscencence.

Discrimination Experience 11.24 \pm 3.14 , Social Withdrawal

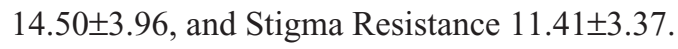

\section{Rating scales before and after treatment according to the demographic and clinical data}

The comparison of scores on BDI-II, BAI, objCGI, and subjCGI before and after treatment did not show differences between subgroups divided according to the sex, employment, marital status, partnership, heredity, and type of psychotherapy (Table 4).

There were no significant interactions between time and comorbidity before and after treatment in a group of comorbidity with anxiety disorder and the group without this comorbidity. The same result was shown in a comparison of groups with and without a personality disorder (Table 4).

Table 3 Mean scores on rating scales at the beginning and the end of the treatment

\begin{tabular}{lllll}
\hline & BDI & BAI & objCGI & subjCGI \\
\hline Beginning of the treatment & $27.76 \pm 9.36$ & $26.90 \pm I I .65$ & $4.40 \pm I .10$ & $4.83 \pm I . I 3$ \\
The end of the treatment & $21.33 \pm I I .33$ & $23.02 \pm \mid 3.72$ & $2.83 \pm 1.20$ & $3.22 \pm I .37$ \\
Statistics & Paired $t$-test: $t=5.603$, & Paired $t$-test: $t=2.767$, & Paired $t$-test: $t=13.69$, & Paired $t$-test: $t=8.157$, \\
& $d f=62 ; P<0.000 I$ & $d f=62 ; P<0.0 I$ & $d f=62 ; P<0.000 I$ & $d f=62 ; P<0.000 I$ \\
\hline
\end{tabular}

Note: Data are presented as mean \pm standard deviation.

Abbreviations: BAI, Beck Anxiety Inventory; BDI, Beck Depression Inventory; df, degrees of freedom; objCGI, Clinical Global Impression - Severity, psychiatrist evaluation; subjCGI, Clinical Global Impression - Severity of the disorder, patient evaluation. 

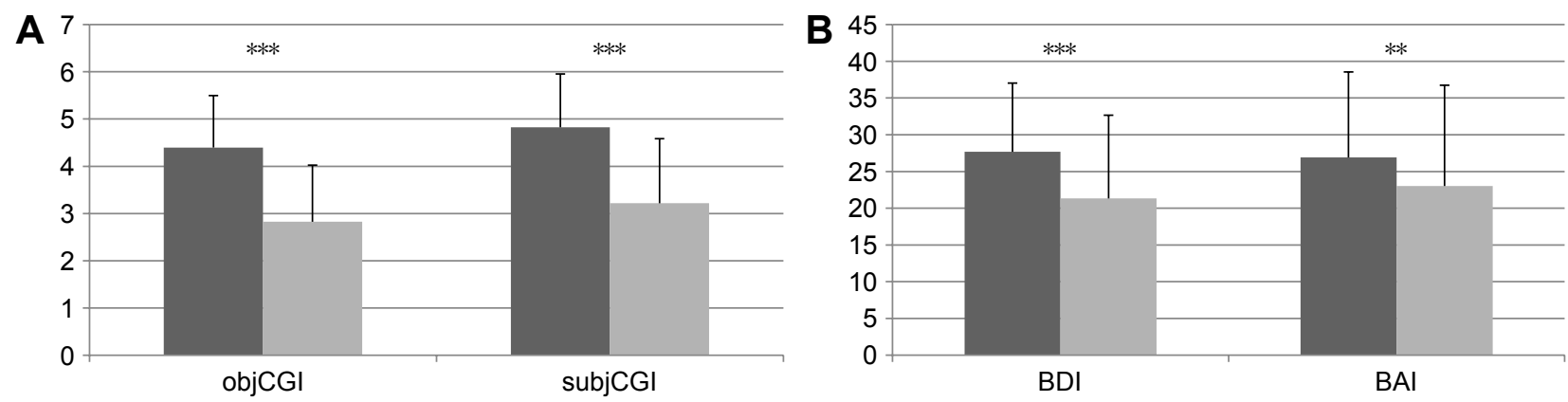

Before treatment After treatment

Figure I Mean objCGI and subjCGI $(\mathbf{A})$ and $\mathrm{BDI}$ and $\mathrm{BAI}(\mathbf{B})$ scores before and after the treatment.

Notes: **Paired $t$-test $P<0.01$; ***Paired $t$-test $P<0.000$ I.

Abbreviations: BAI, Beck Anxiety Inventory; BDI, Beck Depression Inventory; objCGI, Clinical Global Impression - Severity, psychiatrist evaluation; subjCGI, Clinical Global Impression - Severity of the disorder, patient evaluation.

Table 4 Mean scores on BDI, BAI, objCGI, and subjCGI before and after treatment according to qualitative demographic parameters, comorbidity, and psychotherapeutic approach

\begin{tabular}{|c|c|c|c|c|c|c|c|c|}
\hline Variable & BDI-0 & BDI-L & BAI-0 & BAI-L & objCGI-0 & objCGI-L & subjCGI-0 & subjCGI-L \\
\hline Male $(n=20)$ & $25.8 \pm 8.1$ & $17.3 \pm 10.8$ & $23.8 \pm 10.2$ & $19.1 \pm 14.1$ & $4.2 \pm 1.2$ & $2.4 \pm 1.2$ & $4.9 \pm 1.2$ & $2.9 \pm 1.4$ \\
\hline Female $(n=43)$ & $28.6 \pm 9.9$ & $23.2 \pm 11.2$ & $28.4 \pm 12.1$ & $24.9 \pm 13.3$ & $4.6 \pm 1.0$ & $3.0 \pm 1.1$ & $4.8 \pm I .1$ & $3.3 \pm 1.3$ \\
\hline Statistics & $\begin{array}{l}\text { Two-way } \\
F=0.2654 \text {, } \\
\text { Interaction } \\
\text { Time: } P<0 \\
\text { Sex: ns }\end{array}$ & $\begin{array}{l}\text { NOVA: } \\
=40 ; \\
\text { ns } \\
\text { OI }\end{array}$ & $\begin{array}{l}\text { Two-way } \\
F=0.3705, \\
\text { Interaction } \\
\text { Time: ns } \\
\text { Sex: ns }\end{array}$ & $\begin{array}{l}\text { NOVA: } \\
=40 ; \\
\text { ns }\end{array}$ & $\begin{array}{l}\text { Two-way } \\
F=0.2089, \\
\text { Interaction } \\
\text { Time: } P<0 \\
\text { Sex: ns }\end{array}$ & $\begin{array}{l}\text { VOVA: } \\
=40 ; \\
\text { ns } \\
01\end{array}$ & $\begin{array}{l}\text { Two-way } A \\
F=0.7166, d \\
\text { Interaction: } \\
\text { Time: } P<0 \text {. } \\
\text { Sex: ns }\end{array}$ & $\begin{array}{l}\text { OVA: } \\
40 ; \\
\text { s } \\
\text { I }\end{array}$ \\
\hline Employed $(n=30)$ & $28.1 \pm 8.5$ & $19.6 \pm 11.2$ & $27.2 \pm 11.6$ & $21.2 \pm 15.6$ & $4.4 \pm 1.0$ & $2.6 \pm 1.3$ & $4.7 \pm 1.1$ & $3.2 \pm 1.5$ \\
\hline Unemployed $(\mathrm{n}=33)$ & $27.3 \pm 10.2$ & $22.9 \pm 11.4$ & $26.6 \pm 11.9$ & $24.7 \pm 14.7$ & $4.4 \pm 1.2$ & $3.0 \pm 1.4$ & $5.0 \pm 1.2$ & $3.3 \pm 1.3$ \\
\hline Statistics & $\begin{array}{l}\text { Two-way } \\
F=0.3 \text { I I } 2, \\
\text { Interaction } \\
\text { Time: } P<0 \\
\text { Employmer }\end{array}$ & $\begin{array}{l}\text { NOVA: } \\
=60 ; \\
\text { ns } \\
05 \\
\text { t: ns }\end{array}$ & $\begin{array}{l}\text { Two-way } A \\
F=0.4238, \\
\text { Interaction } \\
\text { Time: ns } \\
\text { Employmer }\end{array}$ & $\begin{array}{l}\text { NOVA: } \\
=60 ; \\
\text { ns } \\
\text { t: ns }\end{array}$ & $\begin{array}{l}\text { Two-way } \\
F=0.267 \mathrm{I}, \\
\text { Interaction } \\
\text { Time: } P<0 \\
\text { Employmer }\end{array}$ & $\begin{array}{l}\text { NOVA: } \\
=60 ; \\
\text { ns } \\
001 \\
: \text { ns }\end{array}$ & $\begin{array}{l}\text { Two-way } A \\
F=0.90 \mathrm{I} 3, d \\
\text { Interaction: } \\
\text { Time: } P<0 \text {. } \\
\text { Employmen }\end{array}$ & $\begin{array}{l}\text { OVA: } \\
60 ; \\
\text { s } \\
01 \\
\text { ns }\end{array}$ \\
\hline Single $(n=18)$ & $26.8 \pm 10.4$ & $22.7 \pm 13.7$ & $31.1 \pm 12.6$ & $25.4 \pm 17.0$ & $4.4 \pm 1.3$ & $2.8 \pm 1.3$ & $4.6 \pm 1.4$ & $3.1 \pm 1.4$ \\
\hline Married $(n=24)$ & $26.3 \pm 8.4$ & $18.8 \pm 10.7$ & $23.7 \pm 9.4$ & $20.0 \pm 12.3$ & $4.3 \pm 0.7$ & $2.7 \pm 1.2$ & $4.7 \pm 1.0$ & $3.2 \pm 1.5$ \\
\hline Divorced $(n=15)$ & $30.7 \pm 10.1$ & $23.5 \pm 10.5$ & $26.5 \pm 10.8$ & $24.1 \pm 13.4$ & $4.5 \pm 1.2$ & $3.1 \pm 1.1$ & $5.5 \pm 0.9$ & $3.2 \pm 1.4$ \\
\hline Widow $(n=6)$ & $28.3 \pm 8.6$ & $21.7 \pm 8.0$ & $28.2 \pm 17.1$ & $25.3 \pm 9.5$ & $4.2 \pm 1.2$ & $2.7 \pm 1.2$ & $4.3 \pm 0.8$ & $3.3 \pm 1.0$ \\
\hline Statistics & $\begin{array}{l}\text { Two-way } \\
F=0.3 \mathrm{I} I 3, \\
\text { Interaction } \\
\text { Time: } P<0 \\
\text { Marital: } P<\end{array}$ & $\begin{array}{l}\text { NOVA: } \\
\text { f=78; } \\
\text { ns } \\
005 \\
0.01\end{array}$ & $\begin{array}{l}\text { Two-way } \\
F=0.2039, \\
\text { Interaction } \\
\text { Time: ns } \\
\text { Marital: } P<\end{array}$ & $\begin{array}{l}\text { NOVA: } \\
=78 ; \\
\text { ns } \\
.005\end{array}$ & $\begin{array}{l}\text { Two-way } \\
F=0.252, d f \\
\text { Interaction } \\
\text { Time: } P<0 \\
\text { Marital: } P<\end{array}$ & $\begin{array}{l}\text { NOVA: } \\
78 ; \\
\text { ns } \\
001 \\
.01\end{array}$ & $\begin{array}{l}\text { Two-way } A \\
F=0.5828, d \\
\text { Interaction: } \\
\text { Time: } P<0 \text {. } \\
\text { Marital: ns }\end{array}$ & $\begin{array}{l}\text { OVA: } \\
78 ; \\
\text { s } \\
01\end{array}$ \\
\hline Without partner $(n=26)$ & $27.5 \pm 9.7$ & $22.0 \pm 10.9$ & $26.3 \pm 12.3$ & $24.2 \pm 15.0$ & $4.2 \pm 1.3$ & $2.8 \pm 1.2$ & $5.0 \pm 1.3$ & $3.0 \pm 1.3$ \\
\hline With partner $(n=37)$ & $27.8 \pm 9.3$ & $20.8 \pm 11.7$ & $27.4 \pm 11.4$ & $22.2 \pm 12.9$ & $4.5 \pm 0.9$ & $2.8 \pm 1.2$ & $4.7 \pm 1.0$ & $3.4 \pm 1.4$ \\
\hline Statistics & $\begin{array}{l}\text { Two-way } \\
F=0.4452, \\
\text { Interaction } \\
\text { Time: } P<0 \\
\text { Partner: } P\end{array}$ & $\begin{array}{l}\text { NOVA: } \\
=52 ; \\
\text { ns } \\
005 \\
0.005\end{array}$ & $\begin{array}{l}\text { Two-way } \\
F=0.4992, \\
\text { Interaction } \\
\text { Time: ns } \\
\text { Partner: } P<\end{array}$ & $\begin{array}{l}\text { NOVA: } \\
=52 ; \\
\text { ns } \\
0.05\end{array}$ & $\begin{array}{l}\text { Two-way } \\
F=0.3302, \\
\text { Interaction } \\
\text { Time: } P<0 \\
\text { Partner: } P\end{array}$ & $\begin{array}{l}\text { NOVA: } \\
=52 ; \\
\text { ns } \\
001 \\
0.01\end{array}$ & $\begin{array}{l}\text { Two-way } A \\
F=0.87 \mid 2, d \\
\text { Interaction: } \\
\text { Time: } P<0 \text {. } \\
\text { Partner: ns }\end{array}$ & $\begin{array}{l}\text { OVA: } \\
52 ; \\
\text { s } \\
01\end{array}$ \\
\hline Heredity $(n=30)$ & $29.5 \pm 7.2$ & $21.2 \pm 10.0$ & $27.7 \pm 12.2$ & $23.9 \pm 12.5$ & $4.5 \pm 1.0$ & $2.8 \pm 1.1$ & $4.8 \pm 1.1$ & $3.2 \pm 1.0$ \\
\hline No heredity $(n=33)$ & $26.3 \pm 10.8$ & $21.5 \pm 12.6$ & $26.2 \pm 11.3$ & $22.2 \pm 15.0$ & $4.3 \pm 1.2$ & $2.9 \pm 1.3$ & $4.8 \pm 1.2$ & $3.2 \pm 1.7$ \\
\hline Statistics & $\begin{array}{l}\text { Two-way } \\
F=0.5 \mathrm{I} I 8, \\
\text { Interaction } \\
\text { Time: } P<0 \\
\text { Heredity: } P\end{array}$ & $\begin{array}{l}\text { NOVA: } \\
\text { f=60; } \\
\text { ns } \\
0005 \\
<0.005\end{array}$ & $\begin{array}{l}\text { Two-way } \\
F=0.6791, \\
\text { Interaction } \\
\text { Time: } P<0 . \\
\text { Heredity: } P\end{array}$ & $\begin{array}{l}\text { NOVA: } \\
=60 ; \\
\text { ns } \\
5 \\
<0.0005\end{array}$ & $\begin{array}{l}\text { Two-way } \\
F=0.4055, \\
\text { Interaction } \\
\text { Time: } P<0 \\
\text { Heredity: } P\end{array}$ & $\begin{array}{l}\text { NOVA: } \\
=60 ; \\
\text { ns } \\
001 \\
0.01\end{array}$ & $\begin{array}{l}\text { Two-way } A \\
F=0.978 I, d \\
\text { Interaction: } \\
\text { Time: } P<0 \text {. } \\
\text { Heredity: } n\end{array}$ & $\begin{array}{l}\text { OVA: } \\
60 ; \\
\text { s } \\
\text { OI }\end{array}$ \\
\hline
\end{tabular}


Table 4 (Continued)

\begin{tabular}{|c|c|c|c|c|c|c|c|c|}
\hline & BDI-0 & BDI-L & BAI-0 & BAI-L & objCGI-0 & objCGI-L & subjCGI-0 & subjCGI-L \\
\hline Comorbid anxiety disorder $(n=45)$ & $27.6 \pm 8.7$ & $22.0 \pm 10.6$ & $28.2 \pm 11.9$ & $25.0 \pm 12.3$ & $4.5 \pm 1.3$ & $2.9 \pm 1.2$ & $4.8 \pm 1.1$ & $3.4 \pm 1.4$ \\
\hline Without anxiety disorder $(n=18)$ & $27.9 \pm 11.2$ & $19.7 \pm 13.2$ & $23.6 \pm 10.7$ & $18.1 \pm 16.2$ & $4.1 \pm I .3$ & $2.6 \pm 1.1$ & $5.0 \pm 1.2$ & $2.9 \pm 1.1$ \\
\hline \multirow[t]{5}{*}{ Statistics } & \multicolumn{2}{|c|}{ Two-way ANOVA: } & \multicolumn{2}{|c|}{ Two-way ANOVA: } & \multicolumn{2}{|c|}{ Two-way ANOVA: } & \multicolumn{2}{|c|}{ Two-way ANOVA: } \\
\hline & \multicolumn{2}{|c|}{$F=0.2302, d f=36$} & \multicolumn{2}{|c|}{$F=0.3769, d f=36$} & \multicolumn{2}{|c|}{$F=0.2073, d f=36$} & \multicolumn{2}{|c|}{$F=0.88 \mid 4, d f=36$} \\
\hline & \multicolumn{2}{|c|}{ Interaction: ns } & \multicolumn{2}{|c|}{ Interaction: ns } & \multicolumn{2}{|c|}{ Interaction: ns } & \multicolumn{2}{|c|}{ Interaction: ns } \\
\hline & \multicolumn{2}{|c|}{ Time: $P<0.01$} & \multicolumn{2}{|c|}{ Time: $P<0.001$} & \multicolumn{2}{|c|}{ Time: $P<0.0001$} & \multicolumn{2}{|c|}{ Time: $P<0.0001$} \\
\hline & \multicolumn{2}{|c|}{ Anxiety disorder: ns } & \multicolumn{2}{|c|}{ Anxiety disorder: ns } & \multicolumn{2}{|c|}{ Anxiety disorder: ns } & \multicolumn{2}{|c|}{ Anxiety disorder: ns } \\
\hline Comorbid personality disorder $(n=46)$ & $30.2 \pm 10.2$ & $23.7 \pm 11.2$ & $28.1 \pm 10.2$ & $24.4 \pm 11.6$ & $4.7 \pm 1.1$ & $3.2 \pm 1.1$ & $5.0 \pm 1.1$ & $3.1 \pm 1.5$ \\
\hline Without personality disorder $(n=17)$ & $26.7 \pm 9.0$ & $20.5 \pm 11.4$ & $26.5 \pm 12.2$ & $22.5 \pm 14.5$ & $4.3 \pm I .1$ & $2.7 \pm 1.2$ & $4.8 \pm 1.1$ & $3.3 \pm 1.4$ \\
\hline \multirow[t]{5}{*}{ Statistics } & \multicolumn{2}{|c|}{ Two-way ANOVA: } & \multicolumn{2}{|c|}{ Two-way ANOVA: } & \multicolumn{2}{|c|}{ Two-way ANOVA: } & \multicolumn{2}{|c|}{ Two-way ANOVA: } \\
\hline & \multicolumn{2}{|c|}{$F=0.352, d f=34$} & \multicolumn{2}{|c|}{$F=0.6003, d f=48$} & \multicolumn{2}{|c|}{$F=0.3, d f=48$} & \multicolumn{2}{|c|}{$F=I . \mid 44, d f=48$} \\
\hline & \multicolumn{2}{|c|}{ Interaction: ns } & \multicolumn{2}{|c|}{ Interaction: ns } & \multicolumn{2}{|c|}{ Interaction: ns } & \multicolumn{2}{|c|}{ Interaction: ns } \\
\hline & Time: $P<0$ & 001 & Time: $P<0$ & & Time: $P<0$ & 001 & Time: $P<0.0$ & 01 \\
\hline & Personality & $P<0.05$ & Personality & $P<0.005$ & Personality & & Personality: & \\
\hline Dynamic psychotherapy $(n=39)$ & $26.7 \pm 8.8$ & $20.7 \pm 10.9$ & $27.1 \pm 12.0$ & $22.0 \pm 14.1$ & $4.3 \pm 1.2$ & $2.8 \pm 1.4$ & $4.9 \pm 1.2$ & $3.2 \pm 1.4$ \\
\hline Cognitive-behavioral therapy $(n=24)$ & $29.3 \pm 10.1$ & $22.3 \pm 12.2$ & $26.6 \pm 11.3$ & $24.7 \pm 13.3$ & $4.5 \pm 0.9$ & $2.9 \pm 0.9$ & $4.7 \pm 1.0$ & $3.3 \pm 1.3$ \\
\hline Statistics & Two-way & NOVA: & Two-way A & NOVA: & Two-way $A$ & VOVA: & Two-way Al & OVA: \\
\hline & $F=0.4205$ & $=48$ & $F=0.3426$, & $=48$ & $F=0.4 \mid 47$, & $=48$ & $F=0.7 \mid 35, d f$ & \\
\hline & Interaction & & Interaction & & Interaction & & Interaction: & \\
\hline & Time: $P<0$ & 201 & Time: ns & & Time: $P<0$ & 001 & Time: $P<0.0$ & \\
\hline & Therapy: $P$ & 0.05 & Therapy: ns & & Therapy: $P$ & 0.05 & Therapy: ns & \\
\hline
\end{tabular}

Note: Data are presented as mean \pm SD.

Abbreviations: -0 , beginning of the treatment; BAI, Beck Anxiety Inventory; BDI, Beck Depression Inventory; $d f$, degrees of freedom; ns, not significant; L, end of the treatment; objCGI, Clinical Global Impression - Severity, psychiatrist evaluation; SD, standard deviation; subjCGI, Clinical Global Impression - Severity of the disorder, patient evaluation.

\section{Relative change during the therapy according to demographic and clinical data}

Considering the relative change in BDI-II as a main outcome criterion for the improvement, this change does not correlate significantly with any demographic factors such as the age, the onset of the beginning of the depression, duration of the disorder, number of hospitalizations or subjectively evaluated the severity of disorder in baseline as shown in BDI, BAI, subjCGI, objCGI, not correlated with the dose of the antidepressants. However, the relative improvement in the BDI-II (more negative value means greater improvement) significantly positively correlated with the degree of self-stigma in total score of ISMI, Discrimination Experience (the subscale of ISMI), the severity of dissociation measured by DES, Harm Avoidance (HA), and negatively correlated with the duration of the disorder (Table 5).

The relative objCGI change positively correlates with the level of dissociation measured by DES, ISMI-total score, ISMI subscales Alienation, Discrimination Experience, Social Withdrawal, an overall score of hope measured by ADHS, subscore of ADHS Pathway Thinking, and negatively correlate with SD.

\section{Personality disorders}

A personality disorder was diagnosed in 17 patients $(29.98 \%)$. Patients with a comorbid personality disorder were significantly younger than the patients without a personality disorder (33.06 \pm 10.23 vs $45.67 \pm 1.87$ years; unpaired $t$-test: $t=3.878, d f=61, P<0.001)$. The differences between the subgroups were significant also in age of the onset of the disorder (24.00 \pm 13.23 vs 36.54 \pm 15.28 years; unpaired $t$-test: $t=2.992, d f=61 ; P<0.005)$, in ISMI-total score $(75.47 \pm 19.23$

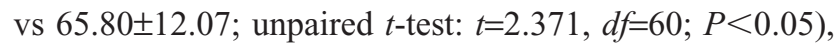
Novelty Seeking (107.1 \pm 13.5 vs 92.35 \pm 11.5 ; unpaired $t$-test: $t=4.184, d f=57 ; P<0.0001), \mathrm{SD}(110.0 \pm 14.3$ vs $123.9 \pm 17.4$, unpaired $t$-test: $t=2.852, d f=57 ; P<0.01), \operatorname{DES}(23.76 \pm 17.79$ vs 14.68 \pm 12.24 ; unpaired $t$-test: $t=2.287, d f=60 ; P<0.05$ ), but not in other measurements (duration of the disorder, ADHS total score and subscales, Harm Avoidance, Reward Dependence, Persistence, Cooperation, Self-Transcendence, rating scales BDI, BAI, subjCGI, and objCGI) at the beginning, but also not with main outcome measures BDI relative change $(-0.158 \pm 0.403$ vs $-0.235 \pm 0.390$, unpaired $t$-test: not significant) and objCGI relative change $(-0.3013 \pm 0.249$ vs $-0.379 \pm 0.212$, unpaired $t$-test: not significant).

\section{Stepwise regression of the relative BDI-Il change}

Because of the various aspects significantly correlated to the BDI-II relative change, a multiple regression analysis (backward stepwise regression) was performed to identify the most important factors linked to the BDI-II relative change as 
Table 5 Correlations of relative change in BDI-II and objCGI with demographic and clinical data

\begin{tabular}{|c|c|c|}
\hline Variables & BDI-L - BDI-0 BAI-0 & objCGI-L - objCGI-0 \\
\hline Age & -0.204 & -0.07899 \\
\hline Onset of the disorder & -0.05437 & $-0.08 \mid 42$ \\
\hline Duration of the disorder & $-0.2449^{(P=0.053)}$ & -0.03704 \\
\hline Number of previous hospitalizations & 0.09845 & -0.1498 \\
\hline BDI-0 & -0.1132 & 0.07405 \\
\hline BAI-0 & 0.1839 & 0.142 \\
\hline objCGI-0 & 0.05708 & 0.1248 \\
\hline subjCGI-0 & 0.05838 & 0.1445 \\
\hline DES & $0.2403^{P(P=0.059)}$ & $0.2733^{\mathrm{P}, *}$ \\
\hline DES-T & 0.08373 & 0.2017 \\
\hline ISMI-Total Score & $0.27 I 2^{\mathrm{P}, *}$ & $0.4955^{\mathrm{P}, * * *}$ \\
\hline Alienation & 0.1989 & $0.3294^{\mathrm{P}, * *}$ \\
\hline Stereotype Endorsement & 0.02452 & 0.1555 \\
\hline Discrimination Experience & $0.3252^{\mathrm{P}, * *}$ & $0.5202^{\mathrm{P}, * * *}$ \\
\hline Social Withdrawal & 0.2089 & $0.2748^{\mathrm{P}, *}$ \\
\hline Stigma Resistance & 0.1192 & 0.0537 \\
\hline ADHS-Total Score & -0.1341 & $-0.2646^{\mathrm{P}, *}$ \\
\hline Pathway Thinking & -0.1279 & $-0.2705^{\mathrm{P}, *}$ \\
\hline Agency & -0.1204 & -0.206 \\
\hline Novelty Seeking & 0.0453 & 0.2038 \\
\hline Harm Avoidance & $0.2594^{\mathrm{P}, *}$ & 0.1442 \\
\hline Reward Dependence & -0.1083 & -0.1951 \\
\hline Persistence & -0.04753 & -0.1062 \\
\hline Self-Directedness & -0.2164 & $-0.3356^{\mathrm{P}, * *}$ \\
\hline Cooperation & -0.2129 & -0.1872 \\
\hline Self-Transcendence & 0.0891 & -0.05161 \\
\hline Antidepressant paroxetine index & $-0.03514(n=59)$ & 0.04076 \\
\hline Anxiolytic alprazolam index & $-0.4429^{P}, *(n=22)$ & -0.2656 \\
\hline Antipsychotc risperidon index & -0.2167 & -0.2135 \\
\hline
\end{tabular}

Notes: $* P<0.05 ; * * P<0.01$; $* * * P<0.001$. $P$, Pearson correlation coefficient.

Abbreviations: BAI, Beck Anxiety Inventory; BDI, Beck Depression Inventory; objCGI, Clinical Global Impression - Severity, psychiatrist evaluation; subjCGI, Clinical Global Impression - Severity of the disorder, patient evaluation; ADHS, Adult Dispositional Hope Scale; ISMI, Internalized Stigma of Mental Illness Scale; DES, Dissocative Experience Scale; DES-T, DES-Taxon.

the dependent variable. The independent variables that were entered were the duration of the disorder, DES, ISMI-Total Score, Discrimination Experience, Harm Avoidance, and comorbid Personality disorder (Table 6). The resultant model explained $15.1 \%$ of the dependent variables. The strongest factors connected to the BDI-II relative change are the duration of the disorder and Discrimination Experience.

\section{Stepwise regression of relative objCGI change}

Because of the several factors significantly related to objCGI relative change, a multiple regression analysis was calculated.

Table 6 Backward stepwise regression with BDI-II relative change as the dependent variable

\begin{tabular}{lllll}
\hline Regressors & B & SE & $\boldsymbol{\beta}$ & Significance \\
\hline Duration of the disorder & -0.013 & 0.006 & -0.276 & 0.029 \\
Discrimination Experience & 0.045 & 0.015 & 0.363 & 0.005 \\
Adjusted $r^{2}=0.151$ & & & & \\
\hline
\end{tabular}

Abbreviations: BDI, Beck Depression Inventory; SE, standard error.
The dependent variable was the objCGI relative change while DES, ISMI-Total Score, Alienation, Discrimination Experience, Social Withdrawal, ADHS-Total Score, Pathway Thinking, and SD were entered as independent variables. The method used was a backward stepwise regression. The resultant model explained $26.8 \%$ of the dependent variable. The strongest factor connected to objCGI relative change was Discrimination Experience (Table 7).

\section{Discussion}

The objective of this analysis was to find the potential psychological factors related to the treatment response in

Table 7 Backward stepwise regression with objCGI relative change as the dependent variable

\begin{tabular}{lllll}
\hline Regressors & B & SE & $\beta$ & Significance \\
\hline Discrimination Experience & 0.0388 & 0.0086 & 0.5307 & 0.0001 \\
Adjusted $r^{2}=0.268$ & & & & \\
\hline Abbrevition
\end{tabular}

Abbreviations: objCGI, Clinical Global Impression - Severity, psychiatrist evaluation; $\mathrm{SE}$, standard error. 
pharmacoresistant patients with the major depressive disorders, who were treated with an antidepressant and psychotherapy. The patients' ratings on all scales were reduced during the treatment. The clinical improvement was achieved in 58.7\% and remission in $36.5 \%$ of patients. The improvement and remission rate is encouraging in light of the fact that these patients had been resistant to the previous outpatient treatment.

The results of the present study show that several clinical or psychosocial variables significantly influenced the treatment change in a patient with a depressive disorder during an intensive 6-week therapeutic inpatient program according to primary outcome criteria.

Looking for the results of correlations with the first outcome measure (the relative BDI-II change), no sociodemographic factor significantly correlated with the therapeutic change, the only duration of the disorder correlated with the BDI-II relative change on the border of statistical significance. However, there were psychological factors that show the correlation with the relative BDI-II change: the level of dissociation in DES, self-stigma in ISMI-total score, Discrimination Experience, and Harm Avoidance.

The second types of factors that could hypothetically contribute to the treatment resistance are psychological factors. The comorbidity with personality disorder did not appear to be an aspect contributing to the treatment efficacy in the study. The present study also showed that individuals with a comorbid personality disorder substantially improved during the treatment, and the relative change of the depressive symptoms was comparable between the groups with and without personality comorbidity. ${ }^{87}$ Several studies published worse treatment outcomes in depressive disorders comorbid with personality disorders. ${ }^{31,111}$ The differences between the results of these studies can be explained by different patient populations; in the present study, there were inpatients with pharmacoresistant depression. Also, this study did not follow the patients after their finishing the hospitalization. However, the small number of subjects in all these studies may distort the results.

The connection between higher dissociation and lower treatment effectiveness was also found in other studies with different diagnostic populations. It has repeatedly been shown that dissociation is one of the factors contributing to the poor treatment outcome in panic disorder ${ }^{12,113}$ and obsessive-compulsive disorder patients. ${ }^{51,57}$ In a previous work, dissociation was an important element influencing treatment effectiveness in the mixed neurotic spectrum and depressive disorders. ${ }^{105}$

The relationship between treatment efficacy and personality traits from the Cloninger theory of personality (specifically harm avoidance and SD) was studied in depression. Higher rates of neuroticism, Harm Avoidance, or lower levels of self-directedness and extraversion are associated with a worse course of the depressive disorder. ${ }^{20,114}$ Treatment-resistant patients with unipolar depression demonstrated low scores for reward dependence and cooperativeness, using the TCI-R. ${ }^{23}$ Both Harm Avoidance and self-directedness have been recognized as features influencing efficiency of pharmacotherapy and psychotherapy in the present study. Other five personality traits of the Cloninger's theory of personality did not relate to treatment effectiveness in the present study. It was shown that the harm avoidance trait decreases the antidepressant efficacy in depression in the study of Quilty et al. ${ }^{115}$ Also in other studies, patients suffering from major depressive disorders with higher scores of Harm Avoidance incline to have no good results in the treatment. ${ }^{27,28}$ Moreover, the Harm Avoidance scores in patients with treatment-resistant depression were significantly higher than the scores of patients with better results. ${ }^{28,30}$

Probably the most significant finding of the present study related to its primary goals is that lower treatment efficacy was associated with higher rates of self-stigma. This result is consistent with findings of other authors who examined the relationship between treatment efficacy and self-stigma in depressed patients and with the results of the study with patients with mixed neurotic spectrum and depressive disorders. ${ }^{58,116}$ Furthermore, the present study confirmed that patients with comorbid personality disorder showed higher rates of self-stigma than those without personality disorders. Therapeutic efficacy also highly negatively correlates with the level of self-stigma in anxiety disorder patients and also in the group of the mixed neurotic spectrum and depressive disorders. ${ }^{58,105}$ There have been several studies focusing on the relationship between self-stigma and treatment effectiveness, related to pharmacotherapy and affective disorders and psychoses. ${ }^{116}$ It was shown that the harm avoidance trait decreases the antidepressant efficacy in depression. Thus, one of the aims of this investigation was to determine whether the self-stigma considerably contributes to the treatment efficiency of the systematic therapy of the major depressive disorders. As for the impact of self-stigma on the combined pharmacological and psychotherapeutic effectiveness, an inverse relationship was found. The firm correlation between internalized stigma and the change of the psychopathology and severity of the disorder during the treatment evaluated by a psychiatrist supports the hypothesis that patients who highly stigmatize themselves improve noticeably less during the systematic treatment than the patients with lower levels of internalized stigma. The most relevant subscale from the 
self-stigma measurement by ISMI was Discrimination Experience, which was the strongest factor that correlated with the therapeutic change in both outcome measures according to regression analysis. The mediators of this association could have been the demoralization brought on the depressive symptoms, as well as the lack of Pathway Thinking caused by low levels of hope, a factor that is connected to the depressive symptoms. ${ }^{104}$

This study desired to determine whether self-stigma (especially subscale Discrimination Experience) is a strong predictor of the therapeutic change or whether it would be eliminated during the regression analyses because other factors would be stronger. It could happen that Harm Avoidance or Dissociation would be better suited to explain the lack of the treatment changes. After all, it is claimed to be temperamental, a largely heritable, trait, and self-stigma is learned during life. While looking at the results of backward stepwise multiple regression analysis, the Discrimination Experience was an only significant factor that influences the relative treatment change in both outcome measures. Other factors that were separately associated with treatment response were eliminated.

The self-stigma subscale Discrimination Experience is the only factor that significantly predicts the second treatment outcome measure - the relative objCGI change.

\section{Limitations}

The group of the depressive patients, who participated in the study, was relatively small and heterogeneous due to the high rate of comorbidity with personality disorders and anxiety disorders for firm conclusions about specific predictors of outcome. A particular risk might pose the prevalent use of the evaluation approaches built on self-evaluation. Some patients did not fill in the questionnaires completely; hence, they had to be excluded from some analyses. The use of these measures and inventories depends on the ability of introspection of the probands and their willingness to be open in the statements.

The diagnoses of major depressive disorder and personality disorders were evaluated by a psychiatrist based on the diagnostic criteria and confirmed by two other qualified psychiatrists. On the other hand, the objectivity of the diagnosis of personality disorders is done only by an experienced psychiatrist, not using the standard tools such as IPDE or SCID-II.

The patients were treated with various psychopharmacs and with two alternative psychotherapeutic approaches that also need to be mentioned. Despite this treatment diversity, self-stigma, especially Discrimination Experience prove to be an influential factor contributing to the treatment efficacy of the patients with depressive disorders.

\section{Conclusion}

Because the current methods of the treatment cannot help all patients with the major depressive disorder, and a high proportion of them remains resistant to the treatment, it is necessary to search for alternative therapeutic approaches for reducing the self-stigma. If further studies confirm these findings, a great perspective for increasing treatment efficacy in major depressive disorder may be strategies for the reduction of self-stigma.

\section{Disclosure}

The authors report no conflicts of interest in this work.

\section{References}

1. Tranter R, O’Donovan C, Chandarana P, Kennedy S. Prevalence and outcome of partial remission in depression. J Psychiatry Neurosci. 2002; 27(4):241-247.

2. Undurraga J, Baldessarini RJ. Randomized, placebo-controlled trials of antidepressants for acute major depression: thirty-year meta-analytic review. Neuropsychopharmacology. 2012;37(4):851-864.

3. Zhang Y, Becker T, Ma Y, Koesters M. A systematic review of Chinese randomized clinical trials of SSRI treatment of depression. BMC Psychiatry. 2014;14:245.

4. Jacobsen PL, Mahableshwarkar AR, Serenko M, Chan S, Trivedi MH. A randomized, double-blind, placebo-controlled study of the efficacy and safety of vortioxetine $10 \mathrm{mg}$ and $20 \mathrm{mg}$ in adults with major depressive disorder. J Clin Psychiatry. 2015;76(5):575-582.

5. Sueki A, Suzuki E, Takahashi H, Ishigooka J. Does early improvement in depressive symptoms predict subsequent remission in patients with depression who are treated with duloxetine? Neuropsychiatr Dis Treat. 2016;12:1269-1273

6. Thase ME, Rush AJ. Treatment-resistant depression. In: Bloom FE, Kupfer DJ, editors. Psychopharmacology: The Fourth Generation of Progress. New York: Raven Press; 1995:1081-1097.

7. Fava M. Diagnosis and definition of treatment-resistant depression. Biol Psychiatry. 2003;53:649-659.

8. Souery D, Papakostas GI, Trivedi MH. Treatment-resistant depression. J Clin Psychiatry. 2006;67(Suppl 6):16-22.

9. Berlim MT, Turecki G. What is the meaning of treatment resistant refractory major depression (TRD)? A systematic review of current randomized trials. Eur Neuropsychopharmacol. 2007;17:696-707.

10. Nil R, Lütolf S, Seifritz E. Residual symptoms and functionality in depressed outpatients: a one-year observational study in Switzerland with escitalopram. J Affect Disord. 2016;197:245-250.

11. Cloninger CR, Svrakic DM, Przybeck TR. A psychological model of temperament and character. Arch Gen Psychiatry. 1993;50: 975-990.

12. Mulder RT, Joyce PR. Relationships of the tridimensional personality questionnaire to mood and personality measures for depressed patients. Psychol Rep. 1994;75:1315-1325.

13. Chien AJ, Dunner DL. The tridimensional personality questionnaire in depression: state versus trait issues. $J$ Psychiatr Res. 1996;30:21-27.

14. Hansenne M, Reggers J, Pinto E, Kjiri K, Ajamier A, Ansseau M. Temperamentand characterinventory (TCI) and depression.JPsychiatr Res. 1999;33(1):31-36.

15. Richter J, Eisemann M, Richter G. Temperament and character during the course of unipolar depression among inpatients. Eur Arch Psychiatry Clin Neurosci. 2000;250:40-47. 
16. Hirano S, Sato T, Narita T, et al. Evaluating the state dependency of the temperament and character inventory dimensions in patients with major depression: a methodological contribution. J Affect Disord. 2002; 69(1-3):31-38.

17. Marijnissen G, Tuinier S, Sijben AES, Verhoeven WMA. The temperament and character inventory in major depression. J Affect Disord. 2002; 70:219-223

18. Farmer A, Mahmood A, Redman K, Harris T, Sadler S, McGuffin P. A sib-pair study of the temperament and character inventory scales in major depression. Arch Gen Psychiatry. 2003;60(5):490-496.

19. Smith DJ, Duffy L, Stewart ME, Muir WJ, Blackwood DH. High harm avoidance and low self-directedness in euthymic young adults with recurrent, early-onset depression. J Affect Disord. 2005;87:83-89.

20. Celikel FC, Kose S, Cumurcu BE, et al. Cloninger's temperament and character dimensions of personality in patients with major depressive disorder. Compr Psychiatry. 2009;50(6):556-561.

21. Spittlehouse JK, Pearson JF, Luty SE, et al. Measures of temperament and character are differentially impacted on by depression severity. $J$ Affect Disord. 2010;126(1-2):140-146.

22. Sasayama D, Hori H, Teraishi T, et al. Difference in temperament and character inventory scores between depressed patients with bipolar II and unipolar major depressive disorders. J Affect Disord. 2011;132(3): 319-324.

23. Takahashi M, Shirayama Y, Muneoka K, Suzuki M, Sato K, Hashimoto K. Personality traits as risk factors for treatment-resistant depression. PLoS One. 2013;8(5):e63756.

24. Joffe RT, Bagby RM, Levitt AJ, Regan JJ, Parker JD. The tridimensional personality questionnaire in major depression. Am J Psychiatry. 1993;150:959-960.

25. Kampman O, Poutanen O. Can onset and recovery in depression be predicted by temperament? A systematic review and meta-analysis. J Affect Disord. 2011;135:20-27.

26. Svrakic DM, Whitehead C, Przybeck TR, Cloninger CR. Differential diagnosis of personality disorders by the seven-factor model of temperament and character. Arch Gen Psychiatry. 1993;50:991-999.

27. Joyce PR, Mulder TR, Cloninger CR. Temperament predicts clomipramine and desipramine response in major depression. J Affect Disord. 1994;30:35-46.

28. Kampman O, Poutanen O, Illi A, et al. Temperament profiles, major depression, and response to treatment with SSRIs in psychiatric outpatients. Eur Psychiatry. 2012;27(4):245-249.

29. Corruble E, Duret C, Pelissolo A, Falissard B, Guelfi JD. Early and delayed personality changes associated with depression recovery? A one-year follow-up study. Psychiatry Res. 2002;109:17-25.

30. Nelsen MR, Dunner DL. Clinical and differential diagnostic aspects of treatment-resistant depression. J Psychiatr Res. 1995;29:43-50.

31. Sato T, Sakado K, Sato S, Morikawa T. Cluster a personality disorder: a marker of worse treatment outcome of major depression? Psychiatry Res. 1994;53(2):153-159.

32. Newton-Howes G, Tyrer P, Johnson T. Personality disorder and the outcome of depression: meta-analysis of published studies. $\mathrm{BrJ}$ Psychiatry. 2006;188:13-20.

33. Sedlackova Z, Prasko J, Latalova K, et al. Psychosocial aspects of resistance in complex treatment of depressive disorder. Neuro Endocrinol Lett. 2015;36(4):354-362.

34. Russell JM, Kornstein SG, Shea MT, et al. Chronic depression and comorbid personality disorders: response to sertraline versus imipramine. J Clin Psychiatry. 2003;64(5):554-561.

35. Kool S, Schoevers R, de Maat S, et al. Efficacy of pharmacotherapy in depressed patients with and without personality disorders: a systematic review and meta-analysis. J Affect Disord. 2005;88(3):269-278.

36. Blom MB, Spinhoven P, Hoffman T, et al. Severity and duration of depression, not personality factors, predict short term outcome in the treatment of major depression. J Affect Disord. 2007;104(1-3):119-126.

37. Maddux RE, Riso LP, Klein DN, et al. Select comorbid personality disorders and the treatment of chronic depression with nefazodone, targeted psychotherapy, or their combination. J Affect Disord. 2009; 117(3):174-179.
38. Bagby RM, Quilty LC, Segal ZV, McBride CC, Kennedy SH, Costa PT. Personality and differential treatment response in major depression: a randomized controlled trial comparing cognitive-behavioural therapy and pharmacotherapy. Can J Psychiatry. 2008;53(6):361-370.

39. Levenson JC, Wallace ML, Fournier JC, Rucci P, Frank E. The role of personality pathology in depression treatment outcome with psychotherapy and pharmacotherapy. J Consult Clin Psychol. 2012;80(5): 719-729.

40. O'Leary D, Costello F. Personality and outcome in depression: an 18-month prospective follow-up study. J Affect Disord. 2001;63(1-3): 67-78.

41. Zimmerman M, Morgan TA, Young D, Chelminski I, Dalrymple K, Walsh E. Does borderline personality disorder manifest itself differently in patients with bipolar disorder and major depressive disorder? J Pers Disord. 2015;29(6):847-853.

42. Galione J, Zimmerman M. A comparison of depressed patients with and without borderline personality disorder: implications for interpreting studies of the validity of the bipolar spectrum. J Pers Disord. 2010;24(6):763-772.

43. Watson S, Chilton R, Fairchild H, Whewell P. Association between childhood trauma and dissociation among patients with borderline personality disorder. Aust N Z J Psychiatry. 2006;40:478-481.

44. Ross CA. Borderline personality disorder and dissociation. J Trauma Dissociation. 2007;8:71-80.

45. American Psychiatric Association. Diagnostic and Statistical Manual of Mental Disorders, Fifth Ed (DSM-5). Arlington: American Psychiatric Association; 2013.

46. Dell PF, O’Neil JA. Dissociation and the Dissociative Disorders: DSM-V and Beyond. New York: Routledge; 2009.

47. Macrì F, Salviati M, Provenzano A, et al. Psychopathological severity index and dissociative symptomatology in a group of nonpsychotic outpatients. J Psychopathology. 2013;19:105-108.

48. Bob P, Freybergh PF, Jasova D, et al. Depression, cortisol and somatoform dissociative symptoms. Neuro Endocrinol Lett. 2008;29(2): 235-239.

49. Pastucha P, Prasko J, Diveky T, et al. Dissociative disorder, and dissociation - comparison with healthy controls. Neuroendocrinol Lett. 2009;30(6):769-773.

50. Pastucha P, Prasko J, Diveky T, et al. Panic disorder, and dissociationcomparison with healthy controls. Neuroendocrinol Lett. 2009;30(6): 774-778.

51. Rufer M, Fricke S, Held D, Cremer J, Hand I. Dissociation and symptom dimensions of obsessive-compulsive disorder: a replication study. Eur Arch Psychiatry Clin Neurosci. 2006;256:146-150.

52. Razska M, Prasko J, Koprivova J, Novak T, Adamcova K. Psychological dissociation in obsessive-compulsive disorder is associated with anxiety level but not with severity of obsessive-compulsive symptoms. Neuroendocrinol Lett. 2009;30(5):624-628.

53. Prasko J, Raszka M, Diveky T, et al. Obsessive-compulsive disorder and dissociation - comparison with healthy controls. Biomed Pap Med Fac Univ Palacky Olomouc Czech Repub. 2010;154(2):179-183.

54. Sar V, Akyüz G, Oztürk E, Alioğlu F. Dissociative depression among women in the community. J Trauma Dissociation. 2013;14(4): 423-438.

55. Pastucha P, Prasko J, Diveky T, et al. Borderline personality disorder, and dissociation - comparison with healthy controls. Act Nerv Super Rediviva. 2009;51(3-4):146-149.

56. Isaac M, Chand PK. Dissociative and conversion disorders: defining boundaries. Curr Opin Psychiatry. 2006;19:61-66.

57. Prasko J, Raszka M, Adamcova K, et al. Predicting the therapeutic response to cognitive behavioral therapy in patients with the pharmacoresistant obsessive-compulsive disorder. Neuroendocrinol Lett. 2009; 30(5):615-623.

58. Ociskova M, Prasko J, Kamaradova D, Grambal A, Latalova K, Sigmundova Z. Relationship between internalized stigma and treatment efficacy in the mixed neurotic spectrum and depressive disorders. Neuro Endocrinol Lett. 2015;35(8):711-717. 
59. Zlotnick C, Shea MT, Zariski A, et al. Stressors and close relationships during childhood and dissociative experiences in survivors of sexual abuse among inpatient psychiatric women. Compr Psychiatry. 1995;36:207-212.

60. Zlotnick C, Shea MT, Pearlstein T, Simpson E, Costello E, Begin A. The relationship between dissociative symptoms, alexithymia, impulsivity, sexual abuse, and self-mutilation. Compr Psychiatry. 1996;37:12-16.

61. Cardena E. The domain of dissociation. In: Lynn SJ, Rhue JW, editors. Dissociation. Clinical and Theoretical Perspectives. New York: Guilford Press; 1994;15-31.

62. Bailer J, Witthöft M, Wagner H, Mier D, Diener C, Rist F. Childhood maltreatment is associated with depression but not with hypochondriasis in later life. J Psychosom Res. 2014;77(2):104-108.

63. Van Veen T, Wardenaar KJ, Carlier IV, Spinhoven P, Penninx BW, Zitman FG. Are childhood and adult life adversities differentially associated with specific symptom dimensions of depression and anxiety? Testing the tripartite model. J Affect Disord. 2013;146(2):238-245.

64. Huh HJ, Kim SY, Yu JJ, Chae JH. Childhood trauma and adult interpersonal relationship problems in patients with depression and anxiety disorders. Ann Gen Psychiatry. 2014;13:26.

65. Van der Kolk BA, Pelcovitz D, Roth S, Mandel FS, McFarlane A, Herman JL. Dissociation, somatization, and affect dysregulation: the complexity of adaptation to trauma. Am J Psychiatry. 1996;153(7):83-93.

66. Glassman L, Weierich M, Hooley J, Deliberto T, Nock M. Child maltreatment, non-suicidal self-injury, and the mediating role of selfcriticism. Behav Res Ther. 2007;45:2483-2490.

67. Perry BP. Child maltreatment: a neurodevelopmental perspective. In: Beauchaine TP, Hinshaw SP, editors, Child and Adolescent Psychopathology. Hoboken, NJ: Wiley. 2008;93-128.

68. Yates TM, Carlson EA, Egeland B. A prospective study of child maltreatment and self-injurious behavior in a community sample. Dev Psychopathol. 2008;20:651-671.

69. Briere J, Hodges M, Godbout N. Traumatic stress, affect dysregulation, and dysfunctional avoidance: a structural equation model. J Trauma Stress. 2010;23:767-774.

70. Shenk CE, Noll JG, Cassarly JA. A multiple mediational tests of the relationship between childhood maltreatment and non-suicidal selfinjury. J Youth Adolesc. 2010;39:335-342.

71. Farber SK. Dissociation, traumatic attachments, and self-harm: eating disorders and self-mutilation. Clin Soc Work J. 2008;36:63-72.

72. Santa Mina EE. Self-harm intentions: can they be distinguished based upon a history of childhood physical and sexual abuse? Can J Nurs Res. 2010;42(4);122-143.

73. Bersani G, Moscariello MA, Bersani FS, et al. Dissociative symptoms in female patients with mood and anxiety disorders: a psychopathological and temperamental investigation. Eur Rev Med Pharmacol Sci. 2014;18(21):3217-3222.

74. Sar V, Akyuz G, Kugu N, Ozturk E, Ertem-Vehid H. Axis I dissociative disorder comorbidity in borderline personality disorder and reports of childhood trauma. J Clin Psychiatry. 2006;67:1583-1590.

75. Snyder CR, Harris C, Anderson JR, et al. The will and the ways: development and validation of an individual-differences measure of hope. J Pers Soc Psychol. 1991;60(4):570-585.

76. Snyder CR. The past and possible futures of hope. J Soc Clin Psychol. 2000;19:11-28.

77. Brouwer D, Meijer RR, Weekers AM, Baneke JJ. On the dimensionality of the dispositional hope scale. Psychol Assess. 2008;20:310-315.

78. Rand KL. Hope and optimism: latent structures and influences of grade expectancy and academic performance. J Pers. 2009;77:231-260.

79. Snyder CR, Sympson SC, Ybasco FC, Borders TF, Babyak MA, Higgins RL. Development and validation of the state hope scale. J Pers Soc Psychol.1996;70:321-335.

80. Magaletta PR, Oliver JM. The hope construct, will, and ways: their relations with self-efficacy, optimism, and general well-being. J Clin Psychol. 1999;55:539-551.

81. Stanton AL, Danoff-Burg S, Cameron CL, et al. Emotionally expressive coping predicts psychological and physical adjustment to breast cancer. J Consult Clin Psychol. 2000;68(5):875-882.
82. Snyder CR. Hope and depression: a light in the darkness. J Soc Clin Psychol. 2004;23:347-351.

83. Snyder CR, Berg C, Woodward JT, et al. Hope against the cold: individual differences in trait hope and acute pain tolerance on the cold pressor task. J Pers. 2005;73:287-312.

84. Arnau RC, Rosen DH, Finch JF, Rhudy JL, Fortunato VJ. Longitudinal effects of hope on depression and anxiety: a latent variable analysis. J Pers. 2006;75:43-64.

85. Oakley LD, Kanter JW, Taylor JY, Duguid M. The self-stigma of depression for women. Int J Soc Psychiatry. 2012;58(5):512-520.

86. Gaudiano BA, Miller IW. Self-stigma and attitudes about treatment in depressed patients in a hospital setting. Int J Soc Psychiatry. 2013; 59(6):586-591

87. Sedlackova Z, Kamaradova D, Prasko J, et al. Treatment adherence and self-stigma in patients with depressive disorder in remission a cross-sectional study. Neuroendocrinol Lett. 2015;36(2):171-177.

88. Borecki L, Gozdzik-Zelazny A, Pokorski M. Personality and perception of stigma in psychiatric patients with depressive disorders. Eur J Med Res. 2010;15(Suppl 2):10-16.

89. Mezinárodní klasifikace nemocí - 10. Revize, MKN-10 (1. vydání); Maxdorf Praha; 1996.

90. Sheehan DV, Lecrubier Y, Sheehan KH, et al. The Mini-International Neuropsychiatric Interview (M.I.N.I.): The development and validation of a structured diagnostic psychiatric interview for DSM-IV and ICD-10. J Clin Psychiat. 1998;59(Suppl 20):22-33; quiz 34-57.

91. Storch EA, Roberti JW, Roth DA. Factor structure, concurrent validity, and internal consistency of the Beck Depression Inventory - Second Edition in a sample of college students. Depress Anxiety. 2004; 19(3):187-189.

92. Preiss M, Vacir K. Beckova sebeposuzovací škála depresivity pro dospělé - BDI-II [Beck self-report depression scale for adults BDI-II]. Brno: Psychodiagnostika; 1999.

93. Guy W, editor. ECDEU Assessment Manual for Psychopharmacology. Rockville, MD: DHEW; 1976.

94. Zaider TI, Heimberg RG, Fresco DM, Schneier FR, Liebowitz MR. Evaluation of the clinical global impression scale among individuals with social anxiety disorder. Psychol Med. 2003;33:611-622.

95. Beck AT, Epstein N, Brown G, Steer RA. An inventory for measuring clinical anxiety: psychometric properties. J Consult Clin Psychol. 1988;56:893-897.

96. De Ayala RJ, Vonderharr-Carlson DJ, Kim D. Assessing the reliability of the Beck Anxiety Inventory scores. Educ Psychol Meas. 2005;65(5):742-756.

97. Kamaradova D, Prasko J, Latalova K, et al. Psychometric properties of the Czech version of the Beck Anxiety Inventory - comparison between diagnostic groups. Neuroendocrinol Lett. 2015;36(7):706-712.

98. Farmer RF, Goldberg LR. A psychometric evaluation of the revised temperament and character inventory (TCI-R) and the TCI-140. Psychol Assess. 2008;20(3):281-291.

99. Black KJ, Sheline YI. Personality disorder scores improve with an effective pharmacology of depression. J Affect Disord. 1997;43:11-18.

100. Tome MB, Cloninger CR, Wason JP, Isaac MT. Serotonergic autoreceptor blockade in the reduction of antidepressant latency: personality variables and response to paroxetine and pindolol. J Affect Disord. 1997;44:101-109.

101. Gillespie NA, Cloninger CR, Heath AC, Martin NG. The genetic and environmental relationship between Cloninger's dimensions of temperament and character. Pers Individ Dif. 2003;35(8):1931-1946.

102. Preiss M, Kucharova J, Novak T, Stepankova H. The temperament and character inventory - revised (TCI-R): a psychometric characteristics of the Czech version. Psychiatr Danub. 2007;19(1-2):27-34.

103. Ocisková M, Sobotková I, Praško J, Mihál V. Standardization of the Czech version of the Snyder's Adult dispositional hope scale [Standardizace české verze Škály dispoziční naděje pro dospělé. In Czech]. Psychologie a její kontexty. 2016;7(1):109-123.

104. Ritsher JB, Otilingam PG, Grajales M. Internalized stigma of mental illness: psychometric properties of a new measure. Psych Res. 2003; 121(1):31-49. 
105. Ociskova M, Praško J, Kamaradova D, et al. Self-stigma in psychiatric patients - standardization of the ISMI scale. Neuroendocrinol Lett. 2014;35(7):624-632.

106. Bernstein EM, Putnam FW. Development, reliability, and validity of a dissociation scale. J Nerv Ment Dis. 1986;174(12):727-735.

107. Spitzer C, Freyberger H, Brähler E, Beutel ME, Stieglitz R. Teststatistische Überprüfung der Dissociative Experiences Scale-Taxon (DES-T) [Psychometric Evaluation of the Dissociative Experiences Scale-Taxon (DES-T)]. Psychother Psychosom Med Psychol. 2015;65(3-4):134-139. German.

108. Waller NG, Ross CA. The prevalence and biometric structure of pathological dissociation in the general population: taxometric and behavior genetic findings. J Abnorm Psychol. 1997;106(4):499-510.

109. Ptacek R, Bob P, Paclt I. Škála disociativních zkušeností - česká verze [Dissociative Experiences Scale - Czech version]. Československa psychologie. 2006;50(3):262-272.

110. European Medicines Agency. Guideline for Good Clinical Practice. London, UK: European Medicines Agency; 2002. Available from: http:/www.edctp.org/fileadmin/documents/EMEA_ICHGCP_Guidelines_July_2002.pdf. Accessed June 17, 2015.
111. Gorwood P, Rouillon F, Even C, Falissard B, Corruble E, Moran P. Treatment response in major depression: effects of personality. BJP. 2010;196:139-142.

112. Segui J, Marquez M, Garcia L, Canet J, Salvador-Carulla L, Ortiz M. Depersonalization in panic disorder: a clinical study. Compr Psychiat. 2000;41:172-178.

113. Gulsun M, Doruk A, Uzun O, Turkbay T, Ozsahin A. Effect of dissociative experiences on drug treatment of panic disorder. Clin Drug Investig. 2007;27:583-590.

114. Grace J, O’Brien, JT. Association of life events and psychosocial factors with early but not late-onset depression in the elderly: implications for possible differences in etiology. Int J Geriatr Psychiatry. 2003;18: $473-478$.

115. Quilty LC, Godfrey KM, Kennedy SH, Begby RM. Harm avoidance as a mediator of treatment response to antidepressant treatment of patients with major depression. Psychother Psychosom. 2010;79(2): 116-122.

116. Cheng-Fang Y, Cheng-Chun C, Yu L, Tze-Chun T, Ju-Yu Y, ChihHung K. Self-stigma and its correlates among outpatients with depressive disorders. Psych Serv. 2005;56(5):599-601.

\section{Publish your work in this journal}

Neuropsychiatric Disease and Treatment is an international, peerreviewed journal of clinical therapeutics and pharmacology focusing on concise rapid reporting of clinical or pre-clinical studies on a range of neuropsychiatric and neurological disorders. This journal is indexed on PubMed Central, the 'PsycINFO' database and CAS, and is the official journal of The International Neuropsychiatric Association (INA). The manuscript management system is completely online and includes a very quick and fair peer-review system, which is all easy to use. Visit http://www.dovepress.com/testimonials.php to read real quotes from published authors. 